\title{
Review \\ Crosstalk between Autophagy and Inflammatory Processes in Cancer
}

\author{
Eun-Ji Lee ${ }^{1,+}$, Hyun-Jeong Kim ${ }^{1,+}$, Min Sik Choi ${ }^{2, *}$ and Ji-Eun Chang ${ }^{1, *}$ \\ 1 Lab of Pharmaceutics, College of Pharmacy, Dongduk Women's University, Seoul 02748, Korea; \\ 20161803@dongduk.ac.kr (E.-J.L.); 20161786@dongduk.ac.kr (H.-J.K.) \\ 2 Lab of Pharmacology, College of Pharmacy, Dongduk Women's University, Seoul 02748, Korea \\ * Correspondence: mschoi@dongduk.ac.kr (M.S.C.); jieun0515@dongduk.ac.kr (J.-E.C.) \\ + Contributed as the co-first author.
}

check for

updates

Citation: Lee, E.-J.; Kim, H.-J.; Choi, M.S.; Chang, J.-E. Crosstalk between Autophagy and Inflammatory Processes in Cancer. Life 2021, 11, 903. https://doi.org/10.3390/life11090903

Academic Editors: Evangelos Koustas and Panagiotis Sarantis

Received: 31 July 2021

Accepted: 28 August 2021

Published: 30 August 2021

Publisher's Note: MDPI stays neutral with regard to jurisdictional claims in published maps and institutional affiliations.

Copyright: (C) 2021 by the authors Licensee MDPI, Basel, Switzerland. This article is an open access article distributed under the terms and conditions of the Creative Commons Attribution (CC BY) license (https:// creativecommons.org/licenses/by/ $4.0 /)$.

\begin{abstract}
Inflammation is an adaptive response to tissue injury, which is a critical process in order to restore tissue functionality and homeostasis. The association between inflammation and cancer has been a topic of interest for many years, not only inflammatory cells themselves but also the chemokines and cytokines they produce, which affect cancer development. Autophagy is an intracellular self-degradative process providing elimination of damaged or dysfunctional organelles under stressful conditions such as nutrient deficiency, hypoxia, or chemotherapy. Interestingly, the signaling pathways that are involved in cancer-associated inflammation may regulate autophagy as well. These are (1) the toll-like receptor (TLR) signaling cascade, (2) the reactive oxygen species (ROS) signaling pathway, (3) the inflammatory cytokine signaling pathway, and (4) the IкB kinase (IKK)/Nuclear factor- $\mathrm{kB}$ (NF- $\mathrm{kB}$ ) signaling axis. Moreover, the studies on the context-specific functions of autophagy during inflammatory responses in cancer will be discussed here. On that basis, we focus on autophagy inhibitors and activators regulating inflammatory process in cancer as useful candidates for enhancing anticancer effects. This review summarizes how the autophagic process regulates these key inflammatory processes and vice versa in various cancers.
\end{abstract}

Keywords: autophagy; cancer; inflammation; toll-like receptor; reactive oxygen species; inflammatory cytokine; IкB kinase/nuclear factor- $\kappa \mathrm{B}$; autophagy inhibitors; autophagy activators

\section{Introduction}

Inflammation is an adaptive response to tissue injury caused by infection, wound, or chemical irritation [1]. It is also known to be an essential process for the restoring of tissue functionality and homeostasis [2]. The relationship between inflammation and cancer has emerged as an important topic for numerous researchers for many years. In 1863, Rudolf Virchow suggested that the origin of cancer might be the chronic inflammation sites. This hypothesis was supported by further studies dealing with the association of chronic inflammatory diseases and enhanced cancer risks [3-5]. Now it has been established that inflammatory cells, as well as the chemokines and cytokines which they produce, strongly influence tumor development [6]. At the initiation stage of the neoplastic process, inflammatory cells act as effective cancer promoters. As the process progresses, they function to encourage cancer spread and metastasis. On the other hand, the inflammatory cells may also suppress tumor growth.

Autophagy is a well-known intracellular elimination process, which provides degradation of damaged and dysfunctional organelles and proteins under highly-stressed conditions. This term came from the Greek word which represents 'self-eating'. Figure 1 shows the overall autophagic process and the inhibitors targeting each step. Several studies have shown that close communication between autophagy and apoptosis exists in determining the fate of cells under pathophysiological conditions [7,8]. It is well known that cells use autophagy as a survival mechanism to avoid cell death. However, when the stress increases 
to a level that exceeds the limits of cellular repair mechanisms, cells inhibit autophagy and initiate the apoptotic cascade [9]. The interaction between autophagy and apoptosis is very complex and entangled with necroptosis; autophagy can function either as an antiapoptotic mechanism or as a proapoptotic mechanism at various stages leading to cell death [10]. Recent research supports the idea that autophagy also plays a pivotal role in regulating inflammation [11]. Various signaling pathways which control tumor-associated inflammation regulate autophagy as well [12]. Inflammatory signals may either induce or inhibit the autophagy process, then autophagy influences tumor-associated inflammation such as induction or inhibition. In addition, autophagy may also regulate key inflammatory cytokines in tumors. Accordingly, autophagy leads to opposing consequences for the tumor since it works as both a tumor suppressor and a tumor promotor [13]. Figure 2 represents autophagy signaling pathways involved in cancer-associated inflammation. In this review, we discuss the relationship between autophagy and the key inflammatory processes in cancer.

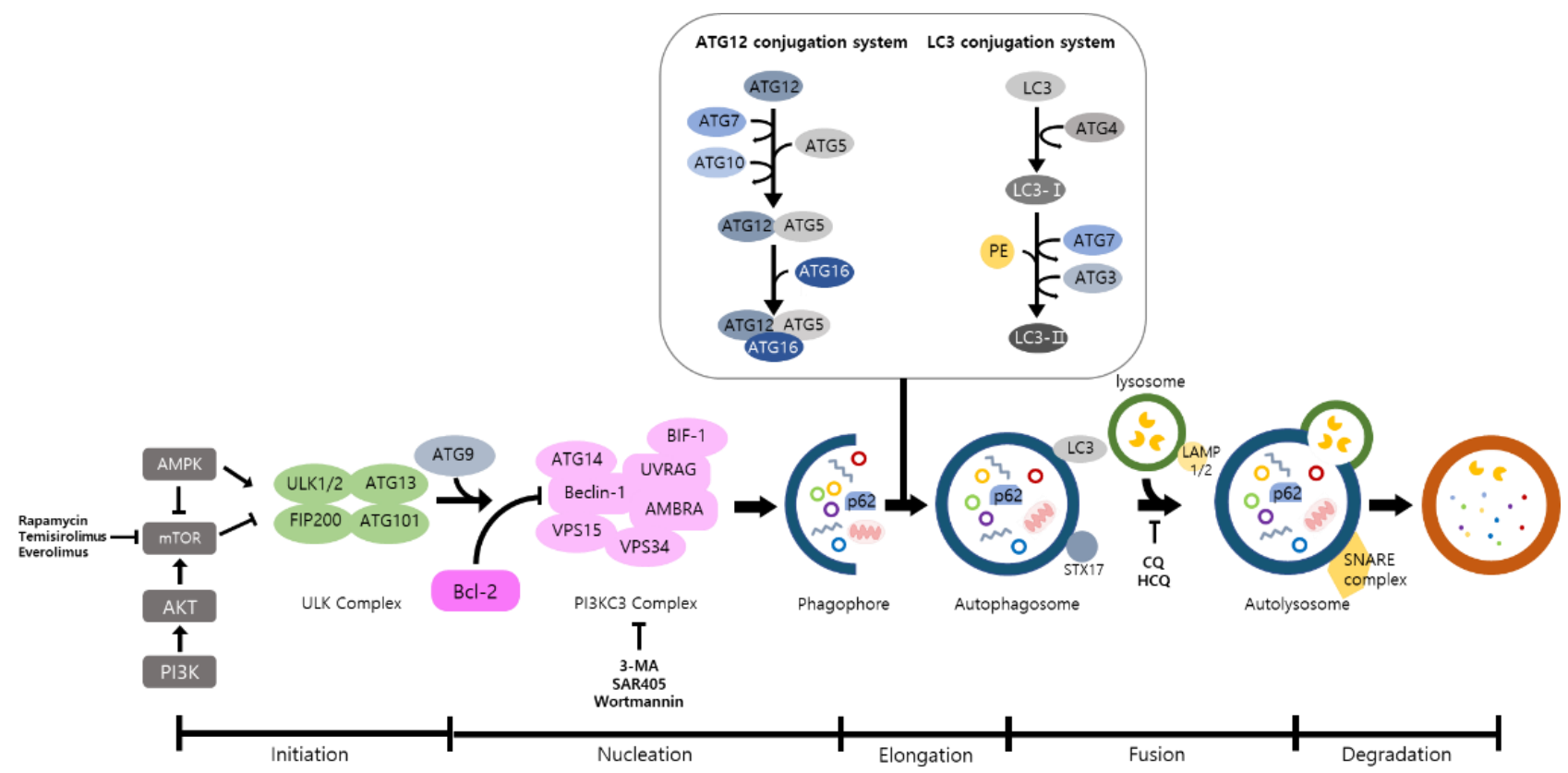

Figure 1. The overall autophagic process and the inhibitors targeting each step. Autophagy includes a multistep procedure: (1) initiation, (2) nucleation, (3) elongation, (4) fusion, and (5) degradation. AMPK and mTOR are major modulators of autophagy and ATGs are deeply associated with this procedure. When the autophagic process is initiated, ULK phosphorylates ATG13 and FIP200 are activated. In nucleation, ULK1 phosphorylates Ambra1, which interacts with Beclin-1, and Beclin-1 forms a PI3KC3 complex with other proteins. After that, cytoplasmic components are enclosed by the phagophore that is expanded to form autophagosomes. These double membranes are fused with lysosomes to form autolysosomes, and various cytoplasmic components are degraded by several enzymes in the autolysosomes. (AMPK: AMP-activated protein kinase; mTOR: mammalian target of rapamycin; ATG: autophagy related gene; ULK: Unc-51 like kinase; FIP200: Focal adhesion kinase family interacting protein of 200-kDa; PI3KC3: Class III phosphatidylinositol 3-kinase). 


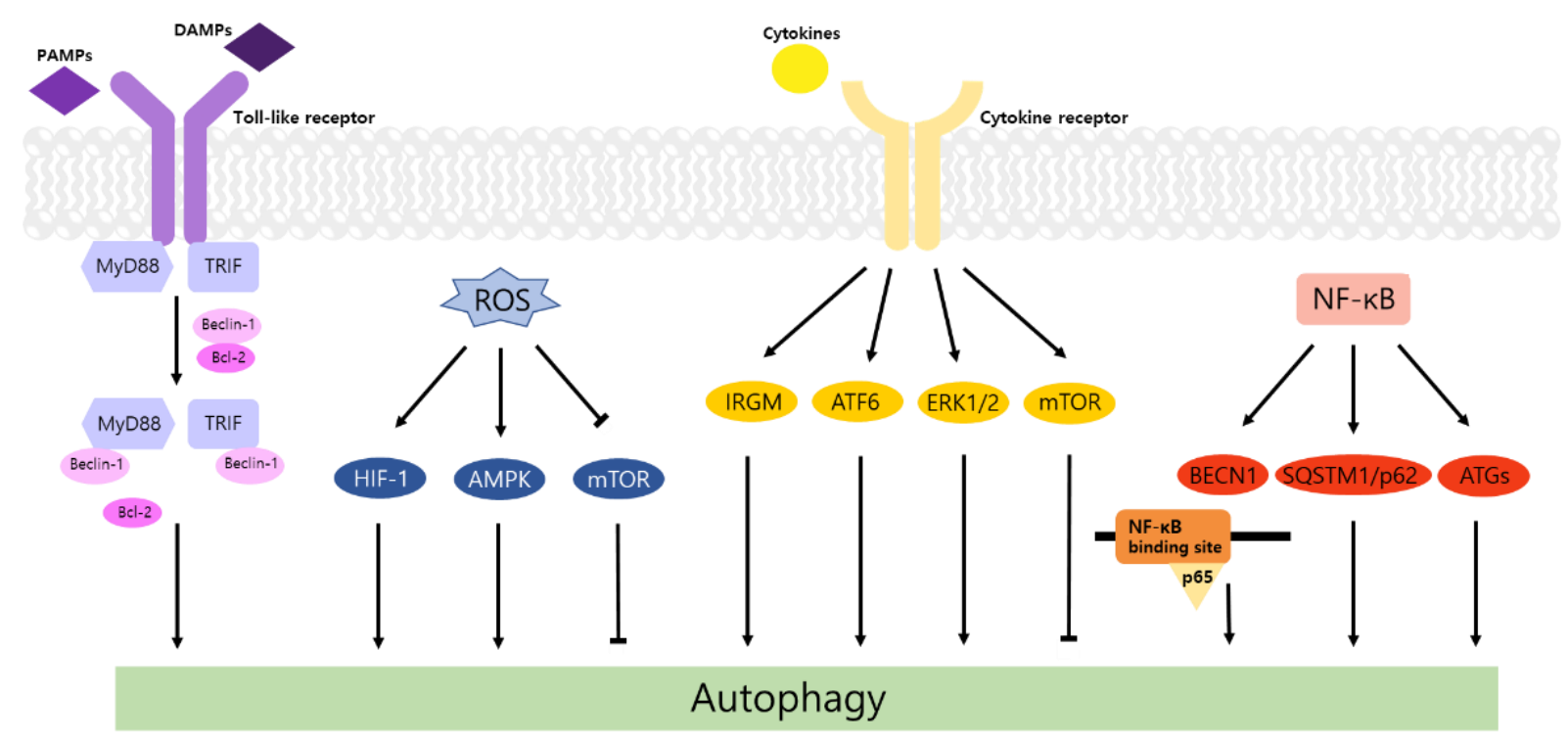

Figure 2. Autophagy signaling pathways involved in cancer-associated inflammation. Four signaling pathways, including (1) toll-like receptor (TLR) signaling cascade, (2) reactive oxygen species (ROS) signaling pathway, (3) inflammatory cytokine signaling pathway, and (4) I $\mathrm{B}$ kinase (IKK)/Nuclear factor- $\mathrm{B} B(\mathrm{NF}-\kappa \mathrm{B})$ signaling axis, are shown in a schematic illustration. See the text for details. (TLR: toll-like receptor; ROS: reactive oxygen species; IKK: IкB kinase; NF- $\kappa B$ : Nuclear factor- $к B$ ).

\section{Autophagy and TLR Signaling in Cancer}

Toll-like receptors (TLRs) are immune regulators that modulate inflammatory response. They specifically recognize damage-associated molecular patterns (DAMPs) and pathogen-associated molecular patterns (PAMPs) by the innate immune system [14]. Then activated TLRs stimulate diverse transcriptional pathways by the myeloid differentiation primary response gene 88 (MyD88)-dependent or MyD88-independent process. Among them, nuclear factor- $\mathrm{KB}(\mathrm{NF}-\mathrm{kB})$, mitogen-activated protein kinase (MAPK), and interferonregulatory factors (IRFs) pathways are associated with the transcription of cancer-related genes that regulate tumor progression, including inflammation, proliferation, angiogenesis, and metastasis. In particular, the NF- $\mathrm{kB}$ cascade induces the expression of cytokines, including tumor necrosis factor alpha (TNF- $\alpha$ ), interleukin-1 beta (IL-1 $\beta$ ), and IL-6, which may cause tumorigenic inflammation [15]. TLRs also regulate the autophagic activity via MyD88- and Toll/IL-1 receptor domain-containing adaptor-inducing interferon- $\beta$ (TRIF)dependent pathways. The conjugation of these proteins and Beclin-1 to TLR4 separates the Bcl-2/Beclin-1 complex and triggers the development of autophagosome [14].

In this regard, numerous studies have demonstrated relations between TLR, autophagy, and cancer. One of these studies suggested that TLR4 induces autophagy and performs a protective function against the progression of hepatocellular carcinoma (HCC) [16]. In TLR4 mutant HCC mice models, apoptosis signal-regulating kinase 1 (ASK1)/p38 MAPK/NF-KB and IRF3/IFN pathways were inhibited, and DNA repair protein Ku70 and inflammatory cytokines such as IL-1 $\beta$, IL- 6 , IL-12, TNF- $\alpha$, and IFN- $\gamma$ were reduced due to the damaged immune system. In addition, the levels of reactive oxygen species (ROS) and p62 were increased while the expression of light chain 3 (LC3)-I/II, Beclin-1 and class III phosphatidylinositol 3-kinase (PI3KC3) were decreased. In terms of tumorigenesis, TLR4 mutant mice showed an accelerated progression of HCC and shortened survival time compared to wild-type HCC mice. In brief, cancer development may be delayed by mitigating genetic instability due to impairment of DNA repair, and this process is closely connected with TLRs and autophagy.

In contrast, TLR4 enhances autophagy induction through beclin 1 (BECN1) ubiquitination by TNF receptor-associated factor 6 (TRAF6) promoting cell migration and invasion in various cancer cell lines [17]. Elevation of LC3-II levels and reduction in cell 
migration/invasion were detected in additional treatment with chloroquine (CQ), the lysosomal inhibitor. Moreover, the expression of IL-6, matrix metalloproteinase 2 (MMP2), and CC chemokine ligand 2 (CCL2) was augmented in A549 cells and was significantly higher in p62KO A549. These results indicate that TLR4 induces autophagy and cell migration/invasion, which is negatively controlled by $\mathrm{p} 62$.

Similarly, TLR9 induces autophagy and stimulates cell proliferation and invasion of HCC. TLR9, ATG, LC3B, and BECN1 were known to be expressed in human HCC cell line, Huh7. Additionally, epithelial mesenchymal transition (EMT) bioindicators, including vimentin and snail showed an increasing pattern as the TLR9 upregulated. Hydroxychloroquine (HCQ) is a suppressor of TLR9 and autophagy. Therefore, HCQ inhibits formation of autolysosome and affects progression of HCC. After treating with HCQ, TLR9 and EMT bioindicators were reduced, and cell viability and migration/invasion were also inhibited [18].

Taken together, TLRs stimulate the activation of autophagy and play a dual role in tumorigenesis. Different outcomes in tumor development are based on the type of TLR or cancer.

\section{Regulation of Autophagy by ROS in Inflammation and Cancer}

ROS is the highly reactive byproduct, which is generated by oxidative phosphorylation in the metabolic process. It is mainly divided into free radical oxygen and nonradical oxygen [19]. In most cases, ROS is generated endogenously by peroxisome and mitochondria. Mitochondrial ROS participates in the normal metabolic pathway; however, excessive ROS may cause oxidative stress and metabolic diseases, leading to cell death and inflammation. ROS has a crucial role in mediating inflammation. Once inflammation occurs, phagocytosis of neutrophils is activated and ROS is increased at the site of infection. ROS regulates the NLR family pyrin domain containing 3 (NLRP3) inflammasome. Thioredoxin-interacting protein (TxNIP) represses thioredoxin (Trx) to induce ROS and increases activity of the inflammasome. Moreover, TxNIP is separated from Trx and interacts with NLRP3 inflammasome [20]. It may transfer pro IL-1 $\beta$, pro IL-18 to IL-1 $\beta$, and IL-18 via active caspase-1 and induce inflammatory response [21].

According to previous studies, ROS is known to stimulate autophagy. In breast and ovarian cancers, ROS enhances activity of autophagy and improves cancer cell survival [22]. Generated ROS induced autophagy by LC3 accumulation and increased the Beclin-1/Bcl-2 ratio [23]. In a recent study, when the ROS level is increased in prostate cancer, acidic vesicular organelles (AVO) and conversion of LC3-I to LC3-II hallmarks of autophagy are triggered [24]. In an oxygen and nutrient deficient environment, excess ROS increases the ratio of AMP / ATP, activates AMP-activated protein kinase (AMPK) [25], and induces formation of autophagosome via activation of UNC-51-like kinase (ULK) and phosphorylation of Beclin-1 [26]. ROS also induces autophagy by repressing the PI3K-Akt-mTOR pathway [27]. When cancer cells are under starvation conditions, $\mathrm{H}_{2} \mathrm{O}_{2}$ is generated, and cysteine protease ATG4 is restrained. This process elevates the formation of autophagy [28]. Recent studies demonstrated that the ROS level is increased in cancer cells and it stimulates autophagy. In colorectal and gastric cancers, beclin-1, the autophagy-related gene is highly expressed [29]. Autophagy impedes DNA mutations by preventing ROS accumulation through elimination of damaged mitochondria. Therefore, inhibition of autophagy via loss of Atg5 and Atg7 helps to initiate tumors by inducing accumulation of ROS and inflammation which is related to IL-1 $\beta$, IL-18 [30].

Cancer cells show a high correlation with hypoxia due to their active metabolism. The translational factor, hypoxia-inducible factor (HIF), is the major mediator of hypoxia. The HIF-1 pathway encourages angiogenesis and provide oxygen to oxygen-deficient tissue [31]. In hypoxia, ROS is generated, and stabilized HIF- $1 \alpha$ interacts with HIF- $1 \beta$ and binds to specific DNA sequence to make epigenetic changes [32]. This stimulates autophagy and promotes survival of cancer cells. Moreover, ROS upregulates cyclin mRNA which progresses the cell cycle from the G1 phase to the S phase. A low ROS level 
decreases cell proliferation and induces apoptosis since G1/S transition is restricted [33]. An excess of ROS, especially $\mathrm{H}_{2} \mathrm{O}_{2}$, reduces activity of MAP kinase phosphatase 3 (MKP3) and activates extracellular signal-regulated kinase (Erk)1/2 [34] to promote cell survival and adhesion-independent cell growth [35].

NADPH oxidase 2 induces ROS production and deactivates AMPK increasing colon cancer metastasis [36]. In addition, other important sources of ROS generation such as mitochondrial electron transport chain complexes [37], xanthine oxidase [38], and cyclooxygenase-2 [39] also play critical roles in the regulation of autophagy and the inflammatory process in cancer.

Taken together, ROS correlates with the whole inflammation process. Inflammatory factors influence activation of autophagy. ROS production is related to massive metabolic process in cancers and this leads to the autophagy process.

\section{Autophagy and Inflammatory Cytokines in Cancer}

Cytokines, products of immune and other cells, bind to specific receptors leading to a pleiotropic activity. This activity induces distinct effects of cytokines on different cells [40]. Moreover, cytokines act as a crucial mediator in inflammatory responses [40] that are augmented by some proinflammatory cytokines, such as IFN- $\gamma$ [41], TNF- $\alpha$ [42], IL-1 $\beta$ [43], IL-6 [44], and IL-8 [45]. The interaction between cytokines and autophagy may lead to various results in tumor development. According to previous studies, inflammatory cytokines may either activate or inactivate autophagy in cancer.

IFN- $\gamma$ induces autophagy and inhibits tumor growth in the human lung epithelial cancer cell line, A549. p62 degradation and LC3 conversion indicating the formation of autophagosome were observed in A549 cells treated with IFN- $\gamma$. Additional treatment with CQ caused the accumulation of p62 and LC3-II. By silencing immunity-related GTPase family M protein (IRGM) and activating transcription factor 6 (ATF6) via shRNA, it was confirmed that IRGM- and ATF6-related signaling pathways were associated with autophagy induced by IFN- $\gamma$. Moreover, IFN- $\gamma$ signaling not only impeded cell proliferation but also played cytotoxic roles including stimulation of apoptotic or nonapoptotic cell death. In shAtg5, lactate dehydrogenase (LDH) activity, which means cytotoxicity, was attenuated compared to shLuc as a negative control [41].

TNF- $\alpha$ has shown inconsistent effects on autophagic activity. In the breast cancer cell line, MCF-7, TNF- $\alpha$ triggered autophagy via the ERK1/2 signaling pathway [46]. On the other hand, TNF- $\alpha$ inhibited autophagic activity induced by trovafloxacin (TVX) in the HepG2 human HCC cell line [42]. TVX, a hepatoxic drug, induced autophagy by suppressing the mammalian target of rapamycin (mTOR) pathway, leading to protective roles against cytotoxicity. TNF- $\alpha$ prompted mTOR pathway through phosphorylation of p70S6K, which led to inhibition of autophagy. Thus, LC3-II and GFP-LC3 puncta were attenuated, and cell viability was reduced in TVX-treated HepG2 cells after treatment with TNF- $\alpha$.

IL-6 alleviates the induction of autophagy during tumor progression. In ovarian cancer cell NIH-OVCAR3, IL-6 blocked the accumulation of autophagosome and GFP-LC3 puncta at the area, which is deeply involved in migration activity. Furthermore, it was observed that cell migration was suppressed by IL-6 stimulation. These findings are associated with the expression of ARH-1 and AKT/mTOR/signal transducer and activator of transcription 3 (STAT3) pathway. ARH-1 acts as an autophagy inducer combining with Beclin-1 and activating the PI3KC3 complex. Data showed that IL-6 decreased the expression of ARH-1 and stimulated the phosphorylation of AKT, mTOR, and STAT3 and in turn, led to cell invasion [44].

Similarly, IL-8 secreted by cancer-associated fibroblasts (CAFs) also reduces autophagy and stimulates cell migration of ovarian cancer [45]. CAFs, major components of stromal cells, are included in the tumor microenvironment (TME) with immune cells and the extracellular matrix (ECM). The interplay between the tumor cell and TME, which is closely related to cytokines and autophagy, influences tumorigenesis [47]. Ovarian cancer- 
associated fibroblasts (OVCAFs) secreted a greater amount of IL-8 than ovarian normalassociated fibroblasts (OVNFs). Due to enhanced IL-8, LC3-II/LC3-I decreased, and p62 accumulation increased in human ovarian cancer cell lines. Moreover, cell migration was promoted in a wound healing assay.

Autophagy also regulates the level of cytokines in several cancers. Induced autophagy in CAFs can stimulate secretion of IL-6 and IL-8 followed by aggressive tumor development. In head and neck squamous cell carcinoma (HNSCC) cell lines, CAFs showed a potent autophagic activity compared to normal fibroblast (NF) and an increase in LC3-II under $\mathrm{CQ}$ treatment. Moreover, the outcomes of this study displayed a decrease in the density of IL- 6 and IL- 8 through knockdown of Beclin- 1 and a reduction in cell migration and invasion of the tumor in siBECN, siATG7, or CQ-treated CAF-CM. The addition of IL-6 and IL-8 to siBECN promoted cell migration. Importantly, autophagy and cytokines such as IL-6 and IL-8 form a feedback loop during this process. IL-6 and IL- 8 secreted by CAFs or HNSCC cells may stimulate CAF autophagy [48].

Pancreatic stellate cells (PSCs), which are part of stromal cells in TME, regulate tumor deterioration by interacting with pancreatic cancer cells (PCCs). Induced autophagy in PSCs elicits a change from inactive PSCs to active PSCs, which release cytokines and ECM. These released factors are associated with the invasion and migration of PCCs. Based on experimental data, LC3 expression was confirmed in activated PSCs. In CQ-treated PSCs, reduced autophagy resulted in the accumulation of LC3-II and p62. By knocking down Atg7 to inhibit the autophagy, the production of IL-6 decreased in PSCs, and the migration and invasion of PCCs were delayed [49]. As mentioned above, autophagy may prompt the secretion of IL-6. However, another study suggests that autophagy may reduce the IL-6. In $66 \mathrm{cl} 4$ breast cancer cell lines from mice, which spread to the lung, autophagic activity was substantially intensified, and LC3-II was increased in CQ- treated 66cl4 cells. Moreover, an increase in IL-6 and decrease of cell viability were observed upon treatment with CQ [50].

In summary, cytokines and autophagy represent protumor or antitumor effects under the unclear roles for each other, and the mechanisms have not been completely understood. The results discussed above showed the relation between the duality of autophagy in tumorigenesis and cytokines. Generally, it is known that IFN- $\gamma$, TNF- $\alpha$, and IL- 6 promote autophagy while IL-10 inhibits autophagy via diverse signaling cascades [51]. However, in this review we suggested that TNF- $\alpha$ and IL- 6 may both promote and inhibit autophagy in certain cases. The action of autophagy on cytokine secretion has also been suggested. Autophagy increases the production of IL- 6 and TNF- $\alpha$ in diverse cell types, which induces innate immune responses [51], and similar results were observed in cancer. Conversely, some studies showed that autophagy inhibited the expression of IL-6 [50] and TNF- $\alpha$ [52], and further studies are required to determine the relationship with tumorigenesis.

\section{Interaction between IKK/NF- $\kappa B$ Axis and Autophagy in Cancer}

As mentioned above, it can be seen that NF- $\mathrm{BB}$ is a key molecule involved in both TLR-, ROS-, and cytokine-related mechanisms interacting with autophagy in the inflammatory process in cancer. The correlation between NF- $\mathrm{BB}$ itself and cancer has been elucidated [53]. The key point is that NF- $\kappa B$ regulates tumor-promoting inflammation or antitumor immune processes through crosstalk with signaling mechanisms related to proteins such as STAT3, p53, and mTOR [54-56]. In this section, among these regulatory mechanisms, we would like to review the relationship between the autophagy process and the NF- $\kappa \mathrm{B}$ pathway in cancer.

In promoting or limiting tumorigenesis, autophagy and NF- $\mathrm{B}$ B regulate each other's activity through complex interactions $[57,58]$. Among the various experimental results related to these interactions, the following three potential mechanisms have been suggested.

First, NF- $\mathrm{BB}$ enhances autophagy by inducing the expression of BECN1, SQSTM1/p62, and other autophagy-related proteins. A conserved NF- $\mathrm{BB}$ binding site in the promoter region of the human and murine BECN1 gene is also known as Atg6 [59]. As this binding site in the BECN1 promoter region interacts with p65, induction of p65 by stimuli involving 
inflammatory processes is linked to BECN1 upregulation and the following autophagy induction. In another study, it has been reported that NF- $\mathrm{kB}$ positively regulates $\mathrm{p} 62$ expression [60]. The results have shown that chloroquine, an autophagy inhibitor, increased the p62 protein level not only by increasing p62 stability but also by increasing p62 expression. Using NF- $\mathrm{kB}$ inhibitors and RELA knockdown, it has been found that NF- $\mathrm{kB}$ is required for chloroquine-induced expression and upregulation of $\mathrm{p} 62$.

Second, autophagy controls the I $\kappa \mathrm{B}$ kinase (IKK)-NF- $\mathrm{kB}$ signaling axis and vice versa $[57,58]$. Hsp90, a molecular chaperone, is a key stability factor for IKK signal activation [61]. It has been known that acute stress can induce the dissociation of Hsp90 from the IKK complex, which results in the inhibition of NF- KB signaling [62]. In this regard, it has been demonstrated that geldanamycin, an Hsp90 inhibitor, increased the degradation of IKK ( $\alpha$ and $\beta$ ) through autophagy. Moreover, it was confirmed that ubiquitination and proteasomal degradation were not involved in this IKK degradation [63]. In contrast, it has been demonstrated that starvation stimulated Atg5, BECN1, and LC3 expression in the IKK-dependent but NF-KB-independent manner [64]. These results suggest that IKK can induce autophagy through the expression of autophagy related genes (ATGs) without the involvement of NF- $\mathrm{kB}$ activation. In addition, it has been reported that several autophagy inducers increased autophagic flux through IKK complex activation [65].

Thirdly, contrary to the above, there have been several reports in which NF- $\mathrm{KB}$ signaling acts negatively on the autophagic process. These cases can be broadly divided into the following two categories. One is that NF- $\mathrm{kB}$ signaling activation stimulates the expression of autophagy repressor proteins, such as Bcl-2 and Bcl-xL [66,67]. The other is that NF- $\mathrm{kB}$ signaling activation suppresses the expression of autophagy inducer proteins, including JNK1 and BCL2 interacting protein 3 (BNIP3) $[68,69]$.

The above studies demonstrate that the NF- $\mathrm{kB}$ signaling pathway can control autophagy and vice versa. Considering that NF- $\mathrm{kB}$ acts as a key regulator of the inflammatory process, the interaction between NF- $\mathrm{KB}$ signaling and the autophagic process in cancer should be clarified. The interaction between autophagy and the IKK-NF- $\mathrm{kB}$ axis is described in Figure 3. Table 1 summarizes the signaling pathways and autophagy in various cancer types.

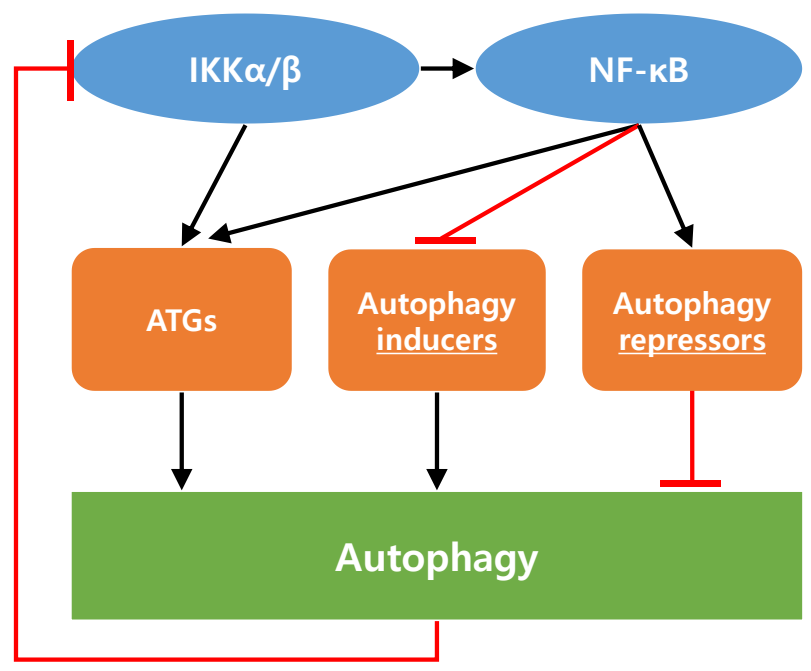

Figure 3. Interaction between autophagy and the IKK-NF- $\mathrm{BB}$ axis. Both IKK and NF- $\mathrm{B}$ can enhance autophagy by inducing the expression of autophagy-related proteins. Increased autophagic flux can inhibit IKK signaling by degrading IKK components. NF- $\mathrm{KB}$ signaling can act negatively on the autophagic process through the increase in autophagy repressors or through the decrease in autophagy inducers. Refer to the main text for proteins in each category in detail. 
Table 1. Signaling Pathways and Autophagy in Various Cancer Types.

\begin{tabular}{|c|c|c|c|c|}
\hline Cancer Types & Signaling Pathways & Autophagy & Therapeutic Effects & Refs. \\
\hline \multirow{3}{*}{ Hepatocellular Carcinoma } & TLR4 & $\uparrow$ & Positive & [16] \\
\hline & TLR9 & $\uparrow$ & Negative & [18] \\
\hline & TNF- $\alpha$ & $\downarrow$ & Positive & [42] \\
\hline Colorectal cancer & ROS & $\uparrow$ & Positive & [23] \\
\hline Prostate Cancer & ROS & $\uparrow$ & Positive & {$[24]$} \\
\hline Lung Cancer & IFN- $\gamma$ & $\uparrow$ & Positive & {$[41]$} \\
\hline \multirow{2}{*}{ Breast Cancer } & TNF- $\alpha$ & $\uparrow$ & Negative & [46] \\
\hline & IL-6 & $\downarrow$ & Positive & [50] \\
\hline \multirow{2}{*}{ Ovarian Cancer } & IL-6 & $\downarrow$ & Negative & {$[44]$} \\
\hline & IL-8 & $\downarrow$ & Negative & [45] \\
\hline $\begin{array}{l}\text { Head and Neck Squamous } \\
\text { Cell Carcinoma }\end{array}$ & IL-6, IL-8 & $\uparrow$ & Negative & [48] \\
\hline Pancreatic Cancer & IL-6 & $\uparrow$ & Positive & [49] \\
\hline
\end{tabular}

\section{Autophagy Inhibitors and Activators for Cancer Treatment}

The role of autophagy in cancer still remains controversial. Autophagy may possess dual roles in cancer development as inhibitors and activators. Inhibition of autophagy may induce sensitized cancer cells leading to enhanced antitumor efficacy over standard cancer treatments such as chemotherapy and radiotherapy. On the other hand, activation of autophagy increases tumor cell death from apoptosis-resistant cells since excessive autophagy plays a critical role in the pro-death pathway. Numerous studies evaluating the anti-tumor effect of using autophagy inhibitors and activators are already completed or ongoing. In this section, we focus on autophagy inhibitors and activators, which influence inflammation therefore enhancing anticancer effects.

\subsection{Autophagy Inhibitors for Cancer Treatment}

3-Methyladenine (3-MA) is one of the well-known autophagy specific inhibitors. It was first discovered by Seglen et al. in 1982 [70]. Phosphoinositide 3-kinase (PI3K) and Vps34 are the molecular targets for 3-MA which regulate autophagy process. Inhibiting autophagy with 3-MA in cancer may stimulate ROS formation and treatment with cytotoxic agent increases ROS accumulation. In this manner, Kaminskyy et al. suggested that blocking autophagy leads to reduced lung cancer cell proliferation and enhanced apoptosis [71]. Interestingly, Yoon et al. discovered that blocking autophagy with 3-MA in HeLa cells decreases ROS generation leading to inactivation of proinflammatory STAT3 and IL6 [72]. Finally, cancer cells showed poor survival despite an opposite ROS expression level. From diverse previous studies, pretreatment of 3-MA combined with other anti-cancer agents showed improved antitumor efficacy in various cancer types [73-75]. In addition, Chen et al. reported that inhibition of autophagy with 3-MA in esophageal cancer contributed to radiation sensitization [76]. In contrast, when autophagy was downregulated with 3-MA in melanoma, crosspresentation of tumor antigens were abolished [77]. This led to enhanced tumorigenesis, which revealed the opposite result against aforementioned studies. SAR405 and wortmannin are also PI3K targeted autophagy inhibitors. Combining SAR405 with an mTOR inhibitor, everolimus in renal cancer showed reduced cell proliferation [78]. In addition, inhibited autophagy with wortmannin enhanced the antitumor effect in HeLa cells [79]. 


\subsection{Autophagy Activators for Cancer Treatment}

Rapamycin is a representative autophagy activator, which is categorized as a mTOR inhibitor. It is produced by Streptomyces hygroscopicus exhibiting antifugal, immunosuppressive, and anti-cancer activities [80]. The mTOR signaling pathway takes part in tumor growth and proliferation. From Zhao et al.'s study, when autophagy was activated with rapamycin in ovarian cancer, intracellular ROS levels were decreased, and migration and invasion were inhibited through reversing EMT. Furthermore, expression of Zeb1 was decreased [81]. EMT plays a crucial role in tumor spreading, which leads to metastasis [82]. Zeb1 is also known to be related to metastasis of various cancer types [83,84]. In another study from Yan's group, autophagy was induced with rapamycin treatment in a melanoma metastasis mouse model. STAT1 activity was enhanced with increased antimetastatic effect. In this study, triggering TLR4 and TLR9 showed synergetic antitumor efficacy with rapamycin induced autophagy; therefore, a combination therapy of immunotherapy and autophagy activator was suggested to be a novel therapeutic approach against tumor progression and metastasis. Rapamycin was also reported to be effective in many different cancers $[85,86]$. Temsirolimus and everolimus are rapamycin analogs, which improved the water solubility and stability of rapamycin. Temsirolimus is proved to be effective in the treatment of prostate cancer [87], colorectal cancer [88], and advanced solid tumors [89]. Everolimus has also been investigated in various tumor types such as triple-negative breast cancer [90], renal cell carcinoma [91], and advanced solid tumors [92].

\section{Conclusions}

In summary, we reviewed how inflammation-related signaling regulates to the autophagy process and, conversely, how autophagy controls inflammation-mediated signaling in cancer. We investigated how autophagy may exhibit a variety of functions in inflammation-based signaling that can influence cancer initiation and progression in various ways. As the results on the context-specific functions of autophagy accumulate, its position as a specialized target according to the type or characteristics of cancer is becoming more solid. Despite the role of autophagy in cancer still remaining controversial, elucidating more specific interactions between autophagy and the inflammatory process may provide important clues.

Author Contributions: Conceptualization, M.S.C. and J.-E.C.; investigation, E.-J.L., H.-J.K., M.S.C., and J.-E.C.; writing-original draft preparation, E.-J.L., H.-J.K., M.S.C., and J.-E.C.; writing-review and editing, M.S.C. and J.-E.C.; supervision, M.S.C. and J.-E.C. All authors have read and agreed to the published version of the manuscript.

Funding: This research received no external funding.

Institutional Review Board Statement: Not applicable.

Informed Consent Statement: Not applicable.

Conflicts of Interest: The authors declare no conflict of interest.

\section{Abbreviations}

\begin{tabular}{ll}
\hline TLR & Toll-Like Receptor \\
\hline DAMP & damage-associated molecular pattern \\
PAMP & pathogen-associated molecular pattern \\
MyD88 & myeloid differentiation primary response gene 88 \\
NF- $\mathrm{B} B$ & nuclear factor- $\mathrm{kB}$ \\
MAPK & mitogen-activated protein kinase \\
IRF & interferon-regulatory factor \\
TNF- $\alpha$ & tumor necrosis factor- $\alpha$ \\
IL-1 $\beta$ & interleukin-1 $\beta$ \\
TRIF & Toll/IL-1 receptor domain-containing adaptor-inducing interferon- $\beta$ \\
\hline
\end{tabular}




\begin{tabular}{ll}
\hline TLR & Toll-Like Receptor \\
\hline ASK1 & apoptosis signal-regulating kinase 1 \\
ROS & reactive oxygen species \\
LC3 & light chain 3 \\
PI3KC3 & class III phosphatidylinositol 3-kinase \\
BECN1 & beclin 1 \\
TRAF6 & TNF receptor-associated factor 6 \\
CQ & chloroquine \\
MMP2 & matrix metalloproteinase 2 \\
CCL2 & CC chemokine ligand 2 \\
EMT & epithelial mesenchymal transition \\
HCQ & hydroxychloroquine \\
AMPK & AMP-activated protein kinase \\
HIF & hypoxia-inducible factor \\
IRGM & immunity-related GTPase family M protein \\
ATF6 & activating transcription factor 6 \\
ERK & extracellular signal-regulated kinase \\
TVX & trovafloxacin \\
STAT3 & signal transducer and activator of transcription 3 \\
CAF & cancer-associated fibroblast \\
TME & tumor microenvironment \\
ECM & extracellular matrix \\
IKK & IkB kinase \\
PI3K & phosphoinositide 3-kinase \\
ATG & autophagy related gene \\
3-MA & 3-Methyladenine \\
\hline
\end{tabular}

\section{References}

1. Philip, M.; Rowley, D.A.; Schreiber, H. Inflammation as a tumor promoter in cancer induction. Semin. Cancer Biol. 2004, 14, 433-439. [CrossRef] [PubMed]

2. Medzhitov, R. Origin and physiological roles of inflammation. Nature 2008, 454, 428-435. [CrossRef]

3. Gurel, B.; Lucia, M.S.; Thompson, I.M.; Goodman, P.J.; Tangen, C.M.; Kristal, A.R.; Parnes, H.L.; Hoque, A.; Lippman, S.M.; Sutcliffe, S.; et al. Chronic inflammation in benign prostate tissue is associated with high-grade prostate cancer in the placebo arm of the prostate cancer prevention trial. Cancer Epidemiol. Biomark. Prev. 2014, 23, 847-856. [CrossRef] [PubMed]

4. McKay, C.J.; Glen, P.; McMillan, D.C. Chronic inflammation and pancreatic cancer. Best Pract. Res. Clin. Gastroenterol. 2008, 22, 65-73. [CrossRef]

5. Michaud, D.S. Chronic inflammation and bladder cancer. Urol. Oncol. Semin. Orig. Investig. 2007, 25, 260-268. [CrossRef] [PubMed]

6. Coussens, L.M.; Werb, Z. Inflammation and cancer. Nature 2002, 420, 860-867. [CrossRef]

7. Goodall, M.L.; Fitzwalter, B.E.; Zahedi, S.; Wu, M.; Rodriguez, D.; Mulcahy-Levy, J.M.; Green, D.R.; Morgan, M.; Cramer, S.D.; Thorburn, A. The Autophagy Machinery Controls Cell Death Switching between Apoptosis and Necroptosis. Dev. Cell 2016, 37, 337-349. [CrossRef]

8. Hou, W.; Han, J.; Lu, C.; Goldstein, L.A.; Rabinowich, H. Autophagic degradation of active caspase-8: A crosstalk mechanism between autophagy and apoptosis. Autophagy 2010, 6, 891-900. [CrossRef] [PubMed]

9. Wu, H.; Che, X.; Zheng, Q.; Wu, A.; Pan, K.; Shao, A.; Wu, Q.; Zhang, J.; Hong, Y. Caspases: A molecular switch node in the crosstalk between autophagy and apoptosis. Int. J. Biol. Sci. 2014, 10, 1072-1083. [CrossRef]

10. Saleem, S. Apoptosis, Autophagy, Necrosis and Their Multi Galore Crosstalk in Neurodegeneration. Neuroscience 2021, 469, 162-174. [CrossRef]

11. Banskota, S.; Wang, H.; Kwon, Y.H.; Gautam, J.; Gurung, P.; Haq, S.; Hassan, F.M.N.; Bowdish, D.M.; Kim, J.A.; Carling, D.; et al. Salicylates ameliorate intestinal inflammation by activating macrophage AMPK. Inflamm. Bowel Dis. 2021, 27, 914-926. [CrossRef] [PubMed]

12. Monkkonen, T.; Debnath, J. Inflammatory signaling cascades and autophagy in cancer. Autophagy 2018, 14, 190-198. [CrossRef] [PubMed]

13. Choi, M.S.; Chae, Y.; Choi, J.W.; Chang, J. Potential Therapeutic Approaches through Modulating the Autophagy Process for Skin Barrier Dysfunction. Int. J. Mol. Sci. 2021, 22, 7869. [CrossRef] [PubMed]

14. Hayat, M.A. Autophagy: Cancer, Other Pathologies, Inflammation, Immunity, Infection, and Aging; Academic Press: Cambridge, UK, 2017; Volume 12, ISBN 0128121475.

15. Javaid, N.; Choi, S. Toll-like receptors from the perspective of cancer treatment. Cancers 2020, 12, 297. [CrossRef] 
16. Wang, Z.; Yan, J.; Lin, H.; Hua, F.; Wang, X.; Liu, H.; Lv, X.; Yu, J.; Mi, S.; Wang, J.; et al. Toll-like receptor 4 activity protects against hepatocellular tumorigenesis and progression by regulating expression of DNA repair protein Ku70 in mice. Hepatology 2013, 57, 1869-1881. [CrossRef]

17. Kim, M.J.; Min, Y.; Im, J.S.; Son, J.; Lee, J.S.; Lee, K.Y. p62 is Negatively Implicated in the TRAF6-BECN1 Signaling Axis for Autophagy Activation and Cancer Progression by Toll-Like Receptor 4 (TLR4). Cells 2020, 9, 1142. [CrossRef]

18. Chen, M.-Y.; Yadav, V.K.; Chu, Y.C.; Ong, J.R.; Huang, T.-Y.; Lee, K.-F.; Lee, K.-H.; Yeh, C.-T.; Lee, W.-H. Hydroxychloroquine (HCQ) Modulates Autophagy and Oxidative DNA Damage Stress in Hepatocellular Carcinoma to Overcome Sorafenib Resistance via TLR9/SOD1/hsa-miR-30a-5p/Beclin-1 Axis. Cancers 2021, 13, 3227. [CrossRef]

19. Krumova, K.; Cosa, G. Chapter 1 Overview of Reactive Oxygen. In Singlet Oxygen: Application in Biosciences and Nanosciences Species; Royal Society of Chemistry: Cambridge, UK, 2016.

20. Zhou, R.; Tardivel, A.; Thorens, B.; Choi, I.; Tschopp, J. Thioredoxin-interacting protein links oxidative stress to inflammasome activation. Nat. Immunol. 2010, 11, 136-140. [CrossRef] [PubMed]

21. Ketelut-Carneiro, N.; Silva, G.K.; Rocha, F.A.; Milanezi, C.M.; Cavalcanti-Neto, F.F.; Zamboni, D.S.; Silva, J.S. IL-18 Triggered by the Nlrp3 Inflammasome Induces Host Innate Resistance in a Pulmonary Model of Fungal Infection. J. Immunol. 2015, 194, 4507-4517. [CrossRef]

22. Liu, W.; Glunde, K.; Bhujwalla, Z.M.; Raman, V.; Sharma, A.; Phang, J.M. Proline oxidase promotes tumor cell survival in hypoxic tumor microenvironments. Cancer Res. 2012, 72, 3677-3686. [CrossRef]

23. Yang, H.-L.; Liu, H.-W.; Shrestha, S.; Thiyagarajan, V.; Huang, H.-C.; Hseu, Y.-C. Antrodia salmonea induces apoptosis and enhances cytoprotective autophagy in colon cancer cells. Aging (Albany NY) 2021, 13, 15964-15989. [CrossRef] [PubMed]

24. Choi, H.D.; Kim, K.Y.; Park, K.I.; Kim, S.H.; Park, S.G.; Yu, S.N.; Kim, Y.W.; Kim, D.S.; Chung, K.T.; Ahn, S.C. Dual role of reactive oxygen species in autophagy and apoptosis induced by compound PN in prostate cancer cells. Mol. Cell. Toxicol. 2021, 17, 41-50. [CrossRef]

25. Pelosse, M.; Cottet-Rousselle, C.; Bidan, C.M.; Dupont, A.; Gupta, K.; Berger, I.; Schlattner, U. Synthetic energy sensor AMPfret deciphers adenylate-dependent AMPK activation mechanism. Nat. Commun. 2019, 10, 1-13. [CrossRef]

26. Wang, C.; Wang, H.; Zhang, D.; Luo, W.; Liu, R.; Xu, D.; Diao, L.; Liao, L.; Liu, Z. Phosphorylation of ULK1 affects autophagosome fusion and links chaperone-mediated autophagy to macroautophagy. Nat. Commun. 2018, 9, 1-15. [CrossRef]

27. Mickymaray, S.; Alfaiz, F.A.; Paramasivam, A.; Veeraraghavan, V.P.; Periadurai, N.D.; Surapaneni, K.M.; Niu, G. Rhaponticin suppresses osteosarcoma through the inhibition of PI3K-Akt-mTOR pathway. Saudi J. Biol. Sci. 2021, 28, 3641-3649. [CrossRef] [PubMed]

28. Abreu, S.; Kriegenburg, F.; Gómez-Sánchez, R.; Mari, M.; Sánchez-Wandelmer, J.; Skytte Rasmussen, M.; Soares Guimarães, R.; Zens, B.; Schuschnig, M.; Hardenberg, R.; et al. Conserved Atg8 recognition sites mediate Atg4 association with autophagosomal membranes and Atg8 deconjugation. EMBO Rep. 2017, 18, 765-780. [CrossRef]

29. Sun, Y.; Liu, J.H.; Jin, L.; Lin, S.M.; Yang, Y.; Sui, Y.X.; Shi, H. Over-expression of the Beclin1 gene upregulates chemosensitivity to anti-cancer drugs by enhancing therapy-induced apoptosis in cervix squamous carcinoma CaSki cells. Cancer Lett. 2010, 294, 204-210. [CrossRef]

30. Katheder, N.S.; Khezri, R.; O’Farrell, F.; Schultz, S.W.; Jain, A.; Schink, M.K.O.; Theodossiou, T.A.; Johansen, T.; Juhász, G.; Bilder, D.; et al. Microenvironmental autophagy promotes tumour growth. Nature 2017, 541, 417-420. [CrossRef]

31. Ebersole, J.L.; Novak, M.J.; Orraca, L.; Martinez-Gonzalez, J.; Kirakodu, S.; Chen, K.C.; Stromberg, A.; Gonzalez, O.A. Hypoxiainducible transcription factors, HIF1A and HIF2A, increase in aging mucosal tissues. Immunology 2018, 154, 452-464. [CrossRef] [PubMed]

32. Palazon, A.; Goldrath, A.; Nizet, V.; Johnson, R.S. HIF Transcription Factors, Inflammation, and Immunity. Immunity 2014, 41, 518-528. [CrossRef] [PubMed]

33. Tai, L.; Huang, C.J.; Choo, K.B.; Cheong, S.K.; Kamarul, T. Oxidative stress down-regulates mir-20b-5p, mir-106a-5p and E2F1 expression to suppress the g1/s transition of the cell cycle in multipotent stromal cells. Int. J. Med. Sci. 2020, 17, 457-470. [CrossRef]

34. Chan, D.W.; Liu, V.W.S.; Tsao, G.S.W.; Yao, K.M.; Furukawa, T.; Chan, K.K.L.; Ngan, H.Y.S. Loss of MKP3 mediated by oxidative stress enhances tumorigenicity and chemoresistance of ovarian cancer cells. Carcinogenesis 2008, 29, 1742-1750. [CrossRef]

35. Chi, T.F.; Khoder-Agha, F.; Mennerich, D.; Kellokumpu, S.; Miinalainen, I.I.; Kietzmann, T.; Dimova, E.Y. Loss of USF2 promotes proliferation, migration and mitophagy in a redox-dependent manner. Redox Biol. 2020, 37, 1-9. [CrossRef]

36. Banskota, S.; Regmi, S.C.; Kim, J.A. NOX1 to NOX2 switch deactivates AMPK and induces invasive phenotype in colon cancer cells through overexpression of MMP-7. Mol. Cancer 2015, 14, 1-14. [CrossRef]

37. Pramanik, K.C.; Boreddy, S.R.; Srivastava, S.K. Role of mitochondrial Electron transport chain complexes in capsaicin mediated oxidative stress leading to apoptosis in pancreatic cancer cells. PLoS ONE 2011, 6, 20151. [CrossRef]

38. Huang, C.C.; Lee, C.C.; Lin, H.H.; Chen, M.C.; Lin, C.C.; Chang, J.Y. Autophagy-regulated ROS from xanthine oxidase acts as an early effector for triggering late mitochondria-dependent apoptosis in cathepsin S-targeted tumor cells. PLoS ONE 2015, 10, 1-20. [CrossRef]

39. Wang, Y.; Mandal, A.K.; Son, Y.O.K.; Pratheeshkumar, P.; Wise, J.T.F.; Wang, L.; Zhang, Z.; Shi, X.; Chen, Z. Roles of ROS, Nrf2, and autophagy in cadmium-carcinogenesis and its prevention by sulforaphane. Toxicol. Appl. Pharmacol. 2018, 353, 23-30. [CrossRef] [PubMed] 
40. Ramani, T.; Auletta, C.S.; Weinstock, D.; Mounho-Zamora, B.; Ryan, P.C.; Salcedo, T.W.; Bannish, G. Cytokines: The good, the bad, and the deadly. Int. J. Toxicol. 2015, 34, 355-365. [CrossRef] [PubMed]

41. Lin, C.F.; Chien, S.Y.; Chen, C.L.; Hsieh, C.Y.; Tseng, P.C.; Wang, Y.C. IFN- $\gamma$ induces mimic extracellular trap cell death in lung epithelial cells through autophagy-regulated DNA damage. J. Interf. Cytokine Res. 2016, 36, 100-112. [CrossRef]

42. Ahn, J.H.; Jegal, H.; Choi, M.S.; Kim, S.; Park, S.M.; Ahn, J.; Han, H.Y.; Cho, H.S.; Yoon, S.; Oh, J.H. TNF $\alpha$ enhances trovafloxacininduced in vitro hepatotoxicity by inhibiting protective autophagy. Toxicol. Lett. 2021, 342, 73-84. [CrossRef] [PubMed]

43. Harris, J.; Hartman, M.; Roche, C.; Zeng, S.G.; O'Shea, A.; Sharp, F.A.; Lambe, E.M.; Creagh, E.M.; Golenbock, D.T.; Tschopp, J.; et al. Autophagy controls IL-1 $\beta$ secretion by targeting Pro-IL-1 $\beta$ for degradation. J. Biol. Chem. 2011, 286, 9587-9597. [CrossRef] [PubMed]

44. Ferraresi, A.; Phadngam, S.; Morani, F.; Galetto, A.; Alabiso, O.; Chiorino, G.; Isidoro, C. Resveratrol inhibits IL-6-induced ovarian cancer cell migration through epigenetic up-regulation of autophagy. Mol. Carcinog. 2017, 56, 1164-1181. [CrossRef]

45. Thongchot, S.; Jamjuntra, P.; Therasakvichya, S.; Warnnissorn, M.; Ferraresi, A.; Thuwajit, P.; Isidoro, C.; Thuwajit, C. Interleukin-8 released by cancer-associated fibroblasts attenuates the autophagy and promotes the migration of ovarian cancer cells. Int. J. Oncol. 2021, 58, 1-14. [CrossRef]

46. Sivaprasad, U.; Basu, A. Inhibition of ERK attenuates autophagy and potentiates tumour necrosis factor- $\alpha$-induced cell death in MCF-7 cells. J. Cell. Mol. Med. 2008, 12, 1265-1271. [CrossRef]

47. Angrini, M.; Varthaman, A.; Cremer, I. Toll-like receptors (TLRs) in the tumor microenvironment (TME): A dragon-like weapon in a non-fantasy game of thrones. In Tumor Microenvironment; Springer: Cham, Switzerland, 2020; pp. 145-173.

48. New, J.; Arnold, L.; Ananth, M.; Alvi, S.; Thornton, M.; Werner, L.; Tawfik, O.; Dai, H.; Shnayder, Y.; Kakarala, K.; et al. Secretory autophagy in cancer-associated fibroblasts promotes head and neck cancer progression and offers a novel therapeutic target. Cancer Res. 2017, 77, 6679-6691. [CrossRef]

49. Endo, S.; Nakata, K.; Ohuchida, K.; Takesue, S.; Nakayama, H.; Abe, T.; Koikawa, K.; Okumura, T.; Sada, M.; Horioka, K.; et al. Autophagy Is Required for Activation of Pancreatic Stellate Cells, Associated With Pancreatic Cancer Progression and Promotes Growth of Pancreatic Tumors in Mice. Gastroenterology 2017, 152, 1492-1506. [CrossRef]

50. Cotzomi-Ortega, I.; Rosas-Cruz, A.; Ramírez-Ramírez, D.; Reyes-Leyva, J.; Rodriguez-Sosa, M.; Aguilar-Alonso, P.; Maycotte, P. Autophagy inhibition induces the secretion of macrophage migration inhibitory factor (MIF) with autocrine and paracrine effects on the promotion of malignancy in breast cancer. Biology 2020, 9, 20. [CrossRef] [PubMed]

51. Mohan, S.; Gupta, D. Crosstalk of toll-like receptors signaling and Nrf2 pathway for regulation of inflammation. Biomed. Pharmacother. 2018, 108, 1866-1878. [CrossRef]

52. Pun, N.T.; Subedi, A.; Kim, M.J.; Park, P.H. Globular adiponectin causes tolerance to LPS-induced TNF- $\alpha$ expression via autophagy induction in RAW 264.7 macrophages: Involvement of SIRT1/FoxO3A axis. PLoS ONE 2015, 10, 1-22. [CrossRef]

53. Taniguchi, K.; Karin, M. NF-B, inflammation, immunity and cancer: Coming of age. Nat. Rev. Immunol. 2018, 18, 309-324. [CrossRef] [PubMed]

54. Grivennikov, S.I.; Karin, M. Dangerous liaisons: STAT3 and NF-kB collaboration and crosstalk in cancer. Cytokine Growth Factor Rev. 2010, 21, 11-19. [CrossRef]

55. Johnson, R.F.; Perkins, N.D. Nuclear factor- $\kappa$ B, p53, and mitochondria: Regulation of cellular metabolism and the Warburg effect. Trends Biochem. Sci. 2012, 37, 317-324. [CrossRef]

56. Hoesel, B.; Schmid, J.A. The complexity of NF-кB signaling in inflammation and cancer. Mol. Cancer 2013, 12, 1-15. [CrossRef]

57. Salminen, A.; Hyttinen, J.M.T.; Kauppinen, A.; Kaarniranta, K. Context-dependent regulation of autophagy by IKK-NF- B signaling: Impact on the aging process. Int. J. Cell Biol. 2012, 1-15. [CrossRef] [PubMed]

58. Baldwin, A.S. Regulation of cell death and autophagy by IKK and NF-kB: Critical mechanisms in immune function and cancer. Immunol. Rev. 2012, 246, 327-345. [CrossRef]

59. Copetti, T.; Bertoli, C.; Dalla, E.; Demarchi, F.; Schneider, C. p65/RelA Modulates BECN1 Transcription and Autophagy. Mol. Cell. Biol. 2009, 29, 2594-2608. [CrossRef] [PubMed]

60. Yang, S.; Qiang, L.; Sample, A.; Shah, P.; He, Y.Y. NF-кB signaling activation induced by chloroquine requires autophagosome, p62 protein, and c-Jun N-terminal Kinase (JNK) signaling and promotes tumor cell resistance. J. Biol. Chem. 2017, 292, 3379-3388. [CrossRef]

61. Broemer, M.; Krappmann, D.; Scheidereit, C. Requirement of Hsp90 activity for IKB kinase (IKK) biosynthesis and for constitutive and inducible IKK and NF-KB activation. Oncogene 2004, 23, 5378-5386. [CrossRef]

62. Salminen, A.; Paimela, T.; Suuronen, T.; Kaarniranta, K. Innate immunity meets with cellular stress at the IKK complex: Regulation of the IKK complex by HSP70 and HSP90. Immunol. Lett. 2008, 117, 9-15. [CrossRef]

63. Qing, G.; Yan, P.; Xiao, G. Hsp90 inhibition results in autophagy-mediated proteasome-independent degradation of IkB kinase (IKK). Cell Res. 2006, 16, 895-901. [CrossRef] [PubMed]

64. Comb, W.C.; Cogswell, P.; Sitcheran, R.; Baldwin, A.S. IKK-dependent, NF-kB-independent control of autophagic gene expression. Oncogene 2011, 30, 1727-1732. [CrossRef] [PubMed]

65. Criollo, A.; Senovilla, L.; Authier, H.; Maiuri, M.C.; Morselli, E.; Vitale, I.; Kepp, O.; Tasdemir, E.; Galluzzi, L.; Shen, S.; et al. The IKK complex contributes to the induction of autophagy. EMBO J. 2010, 29, 619-631. [CrossRef] 
66. Tamatani, M.; Che, Y.H.; Matsuzaki, H.; Ogawa, S.; Okado, H.; Miyake, S.I.; Mizuno, T.; Tohyama, M. Tumor necrosis factor induces Bcl-2 and Bcl-x expression through NFKB activation in primary hippocampal neurons. J. Biol. Chem. 1999, 274, 8531-8538. [CrossRef] [PubMed]

67. Chen, C.; Edelstein, L.C.; Gélinas, C. The Rel/NF-kB Family Directly Activates Expression of the Apoptosis Inhibitor Bcl-x $x_{\mathrm{L}} \cdot$ Mol. Cell. Biol. 2000, 20, 2687-2695. [CrossRef]

68. Gang, H.; Dhingra, R.; Wang, Y.; Mughal, W.; Gordon, J.W.; Kirshenbaum, L.A. Epigenetic regulation of E2F-1-dependent Bnip3 transcription and cell death by nuclear factor- $\mathrm{kB}$ and histone deacetylase-1. Pediatr. Cardiol. 2011, 32, 263-266. [CrossRef]

69. Liu, J.; Lin, A. Wiring the cell signaling circuitry by the NF- $\kappa B$ and JNK1 crosstalk and its applications in human diseases. Oncogene 2007, 26, 3267-3278. [CrossRef] [PubMed]

70. Seglen, P.O.; Gordon, P.B. 3-Methyladenine: Specific inhibitor of autophagic/lysosomal protein degradation in isolated rat hepatocytes. Proc. Natl. Acad. Sci. USA 1982, 79, 1889-1892. [CrossRef] [PubMed]

71. Kaminskyy, V.O.; Piskunova, T.; Zborovskaya, I.B.; Tchevkina, E.M.; Zhivotovsky, B. Suppression of basal autophagy reduces lung cancer cell proliferation and enhances caspase-dependent and -independent apoptosis by stimulating ROS formation. Autophagy 2012, 8, 1032-1044. [CrossRef] [PubMed]

72. Yoon, S.; Woo, S.U.; Kang, J.H.; Kim, K.; Kwon, M.H.; Park, S.; Shin, H.J.; Gwak, H.S.; Chwae, Y.J. STAT3 transcriptional factor activated by reactive oxygen species induces IL6 in starvation-induced autophagy of cancer cells. Autophagy 2010, 6, 1125-1138. [CrossRef]

73. Wang, H.Y.; Peng, Y.; Wang, J.; Gu, A.X.; Li, Q.; Mao, D.W.; Guo, L.Y. Effect of autophagy on the resveratrol-induced apoptosis of ovarian cancer SKOV3 cells. J. Cell. Biochem. 2019, 120, 7788-7793. [CrossRef]

74. Zhao, F.; Feng, G.; Zhu, J.; Su, Z.; Guo, R.; Liu, J.; Zhang, H.; Zhai, Y. 3-Methyladenine-enhanced susceptibility to sorafenib in hepatocellular carcinoma cells by inhibiting autophagy. Anticancer Drugs 2021, 32, 386-393. [CrossRef]

75. Chen, W.C.; Hsu, K.Y.; Hung, C.M.; Lin, Y.C.; Yang, N.S.; Ho, C.T.; Kuo, S.C.; Way, T.D. The anti-tumor efficiency of pterostilbene is promoted with a combined treatment of Fas signaling or autophagy inhibitors in triple negative breast cancer cells. Food Funct. 2014, 5, 1856-1865. [CrossRef] [PubMed]

76. Chen, Y.S.; Song, H.X.; Lu, Y.; Li, X.; Chen, T.; Zhang, Y.; Xue, J.X.; Liu, H.; Kan, B.; Yang, G.; et al. Autophagy inhibition contributes to radiation sensitization of esophageal squamous carcinoma cells. Dis. Esophagus 2011, 24, 437-443. [CrossRef] [PubMed]

77. Li, Y.; Wang, L.X.; Yang, G.; Hao, F.; Urba, W.J.; Hu, H.M. Efficient cross-presentation depends on autophagy in tumor cells. Cancer Res. 2008, 68, 6889-6895. [CrossRef]

78. Pasquier, B. SAR405, a PIK3C3/VPS34 inhibitor that prevents autophagy and synergizes with MTOR inhibition in tumor cells. Autophagy 2015, 11, 725-726. [CrossRef]

79. Lin, J.; Huang, Z.; Wu, H.; Zhou, W.; Jin, P.; Wei, P.; Zhang, Y.; Zheng, F.; Zhang, J.; Xu, J.; et al. Inhibition of autophagy enhances the anticancer activity of silver nanoparticles. Autophagy 2014, 10, 2006-2020. [CrossRef] [PubMed]

80. Park, S.R.; Yoo, Y.J.; Ban, Y.H.; Yoon, Y.J. Biosynthesis of rapamycin and its regulation: Past achievements and recent progress. J. Antibiot. 2010, 63, 434-441. [CrossRef] [PubMed]

81. Zhao, Z.; Zhao, J.; Xue, J.; Zhao, X.; Liu, P. Autophagy inhibition promotes epithelial-mesenchymal transition through ROS/HO-1 pathway in ovarian cancer cells. Am. J. Cancer Res. 2016, 6, 2162-2177.

82. Miow, Q.H.; Tan, T.Z.; Ye, J.; Lau, J.A.; Yokomizo, T.; Thiery, J.P.; Mori, S. Epithelial-mesenchymal status renders differential responses to cisplatin in ovarian cancer. Oncogene 2014, 34, 1899-1907. [CrossRef]

83. Kan, J.; Yen, M.; Wang, J.; Wu, D. Nesfatin-1 / Nucleobindin-2 enhances cell migration, invasion, and epithelial-mesenchymal transition via LKB1/AMPK/TORC1/ZEB1 pathways in colon cancer. Oncotarget 2016, 7, 31336-31349. [CrossRef]

84. Ma, Z.; Li, Y.; Xu, J.; Ren, Q.; Yao, J.; Tian, X. MicroRNA-409-3p regulates cell invasion and metastasis by targeting ZEB1 in breast cancer. IUBMB Life 2016, 68, 394-402. [CrossRef]

85. Takeuchi, H.; Kondo, Y.; Fujiwara, K.; Kanzawa, T.; Aoki, H.; Mills, G.B.; Kondo, S. Synergistic augmentation of rapamycininduced autophagy in malignant glioma cells by phosphatidylinositol 3-kinase/protein kinase B inhibitors. Cancer Res. 2005, 65, 3336-3346. [CrossRef] [PubMed]

86. Carayol, N.; Vakana, E.; Sassano, A.; Kaur, S.; Goussetis, D.J.; Glaser, H.; Druker, B.J.; Donato, N.J.; Altman, J.K.; Barr, S.; et al. Critical roles for mTORC2- and rapamycin-insensitive mTORC1-complexes in growth and survival of BCR-ABL-expressing leukemic cells. Proc. Natl. Acad. Sci. USA 2010, 107, 12469-12474. [CrossRef]

87. Inamura, S.; Hideaki, I.T.O.; Taga, M.; Tsuchiyama, K.; Hoshino, H.; Kobayashi, M.; Yokoyama, O. Low-dose docetaxel enhanced the anticancer effect of temsirolimus by overcoming autophagy in prostate cancer cells. Anticancer Res. 2019, 39, 5417-5425. [CrossRef]

88. Shiratori, H.; Kawai, K.; Hata, K.; Tanaka, T.; Nishikawa, T.; Otani, K.; Sasaki, K.; Kaneko, M.; Murono, K.; Emoto, S.; et al. The combination of temsirolimus and chloroquine increases radiosensitivity in colorectal cancer cells. Oncol. Rep. 2019, 42, 377-385. [CrossRef]

89. Trivedi, N.D.; Armstrong, S.; Wang, H.; Hartley, M.; Deeken, J.; Ruth He, A.; Subramaniam, D.; Melville, H.; Albanese, C.; Marshall, J.L.; et al. A phase I trial of the mTOR inhibitor temsirolimus in combination with capecitabine in patients with advanced malignancies. Cancer Med. 2021, 10, 1944-1954. [CrossRef] [PubMed] 
90. El Guerrab, A.; Bamdad, M.; Bignon, Y.J.; Penault-Llorca, F.; Aubel, C. Co-targeting EGFR and mTOR with gefitinib and everolimus in triple-negative breast cancer cells. Sci. Rep. 2020, 10, 1-12. [CrossRef]

91. Feldman, D.R.; Ged, Y.; Lee, C.H.; Knezevic, A.; Molina, A.M.; Chen, Y.B.; Chaim, J.; Coskey, D.T.; Murray, S.; Tickoo, S.K.; et al. Everolimus plus bevacizumab is an effective first-line treatment for patients with advanced papillary variant renal cell carcinoma: Final results from a phase II trial. Cancer 2020, 126, 5247-5255. [CrossRef]

92. Zhu, M.; Molina, J.R.; Dy, G.K.; Croghan, G.A.; Qi, Y.; Glockner, J.; Hanson, L.J.; Roos, M.M.; Tan, A.D.; Adjei, A.A. A phase I study of the VEGFR kinase inhibitor vatalanib in combination with the mTOR inhibitor, everolimus, in patients with advanced solid tumors. Investig. New Drugs 2020, 38, 1755-1762. [CrossRef] 